\title{
Multi-level selection for hygienic behaviour in honeybees
}

\author{
JA Pérez-Sato ${ }^{1}$, N Châline ${ }^{2}$, SJ Martin, WOH Hughes and FLW Ratnieks ${ }^{3}$ \\ Department of Animal and Plant Sciences, University of Sheffield, Sheffield, UK
}

Disease is one of the main factors driving both natural and artificial selection. It is a particularly important and increasing threat to the managed honeybee colonies, which are vital in crop pollination. Artificial selection for disease-resistant honeybee genotypes has previously only been carried out at the colony-level, that is, by using queens or males reared from colonies that show resistance. However, honeybee queens mate with many males and so each colony consists of multiple patrilines that will vary in heritable traits, such as disease resistance. Here, we investigate whether response to artificial selection for a key resistance mechanism, hygienic behaviour, can be improved using multi-level selection, that is, by selecting not only among colonies as normal but also among patrilines within colonies. Highly hygienic colonies were identified (between-colony selection), and the specific patrilines within them responsible for most hygienic behaviour were determined using observation hives. Queens reared from these hygienic patrilines (within-colony selection) were identified using DNA microsatellite analysis of a wing-tip tissue sample and then mated to drones from a third highly hygienic colony. The resulting colonies headed by queens from hygienic patrilines showed approximately double the level of hygienic behaviour of colonies headed by sister queens from non-hygienic patrilines. The results show that multi-level selection can significantly improve the success of honeybee breeding programs.

Heredity (2009) 102, 609-615; doi:10.1038/hdy.2009.20; published online 4 March 2009

Keywords: Apis mellifera; resistance; parasite; breeding; artificial selection

\section{Introduction}

Disease is a major selective pressure in most organisms. Improving the disease resistance of beneficial organisms is accordingly a common goal of many breeding programs. Disease is particularly important for honeybees, Apis mellifera, and thus for the apicultural and agricultural industries that they support (Beban, 2003; Waite et al., 2003b; Committee on the Status of Pollinators in North America, 2007). The threat posed by parasites is abundantly illustrated by the recent problems caused by Varroa mite in many countries (Ellis and Munn, 2005; Wilkins et al., 2007), and by the occurrence of 'Colony Collapse Disorder' in the USA in 2007 (Cox-Foster et al., 2007). Although chemicals can sometimes be effective at controlling pests and pathogens, they are expensive, residues can make honey unsafe for human consumption, and target organisms such as Varroa have evolved

Correspondence. Current address: $\mathrm{Dr}$ WOH Hughes, Institute of Integrative and Comparative Biology, University of Leeds, Leeds, LS2 9JT, UK.

E-mail: w.o.h.hughes@leeds.ac.uk

${ }^{1}$ Current address: Colegio de Postgraduados Campus Cordoba, Km 348 Carretera Federal Cordoba-Veracruz, Congregación Manuel Leon Amatlan de los Reyes, Cordoba, Veracruz, CP 94946, Mexico.

${ }^{2}$ Current address: LEEC, CNRS UMR 7153, Université Paris 13, 99 Avenue J.B. Clément, 93430 Villetaneuse, France.

${ }^{3}$ Current address: Department of Biological and Environmental Science, University of Sussex, Falmer, Brighton, BN1 9QG, UK.

Received 1 October 2008; revised 29 December 2008; accepted 5 January 2009; published online 4 March 2009 resistance to them in some areas (Floris et al., 2001; Lodesani and Costa, 2005).

Much attention has, therefore, been directed at breeding disease-resistant honeybees. However, the biology of honeybees and other social insects makes this more challenging than in non-eusocial animals (Ratnieks, 1998). One fundamental problem is that 'daughter' and 'mother' colonies are genetically less similar than offspring and parents in non-eusocial species. Consider a situation in which a colony of haplodiploid eusocial insects (ants, bees or wasps) has a trait that arises from the behaviour of the workers, and a new colony is established headed by an outmated queen who is the full sister of these mother-colony workers. The workers in the daughter colony have a probability of 0.375 of sharing nuclear genes identical by descent with the workers in the mother colony. This is less than the parent-offspring probability of 0.5 in non-eusocial animals. Genetic similarity is reduced further if the queen in the mother colony is mated to multiple males (polyandry), as is the case in Apis mellifera, the queens of which mate with approximately 12 males (Estoup et al., 1994; Tarpy et al., 2004). This reduces the probability of sharing alleles from 0.375 to 0.15 , which is more than three times lower than in non-eusocial organisms. Another genetic complication is that some colony-level phenotypes may arise due to particular combinations of individual genotypes in a colony, including combinations of worker genotypes or queen plus worker genotypes (Bienefeld and Pirchner, 1991; Yue et al., 2006; Bienefeld et al., 2007). These are analogous to the 
dominance and other interactions among genes in the breeding of non-eusocial animals and are essentially non-heritable. For example, if a colony of honeybees has some desirable property because of a specific combination of worker patrilines, this could not be passed on to a daughter colony headed by a queen that was a sister to the workers of the mother colony, as the queen would belong to only one patriline. A further complication of social life is that many desirable worker phenotypes are not detectable in individual queens or workers, so that a whole colony has to be reared before the colony-level phenotype can be detected.

One key honeybee defence mechanism that has received considerable attention is hygienic behaviour (reviewed by Spivak and Gilliam (1998)). This behaviour is carried out by workers as a defence against various brood diseases, such as the bacteria Paenibacillus larvae (Rothenbuhler, 1964), the chalkbrood fungus Ascosphaera apis (Milne, 1983) and the mite Varroa destructor (Spivak, 1996). Hygienic behaviour involves the detection by worker honeybees of dead or infected brood, followed by the uncapping of the wax cell and the removal of the larva or pupa (Arathi et al., 2000). The proportion of highly hygienic colonies, defined as those that remove $>95 \%$ of dead brood within $48 \mathrm{~h}$, is normally only around 10-12\% in natural populations (Oldroyd, 1996; Spivak and Gilliam, 1998; Waite et al., 2003a). However, this proportion can be increased through artificial colony-level selection (Spivak and Gilliam, 1998). This starts by screening a large number of colonies to detect the most hygienic colonies, from which queens and/or drones are reared. A hygienic line of colonies are then obtained after at least four generations by crossing drones and daughter queens from the most hygienic colonies using either artificial insemination or natural mating (Palacio et al., 2000; Spivak and Reuter, 2001).

Although colony-level selection has proved successful, the response to selection could potentially be improved if the breeding programme also included intracolony selection. The rationale behind this is that much of the genetic heterogeneity in a honeybee colony comes about because mother queens mate with multiple males (Estoup et al., 1994; Tarpy et al., 2004). The queens use sperm from these males randomly (Franck et al., 1999, 2002), and so colonies consist of many distinct genetic lineages (patrilines) that are the offspring of different fathers. Hygienic behaviour is behaviourally dominant, meaning that a colony has a hygienic colony-level phenotype even if only a small proportion of workers are hygienic (Arathi et al., 2000). Thus, a colony with only one or a few hygienic patrilines would be hygienic. As a result, the majority of daughter queens reared from a hygienic colony may themselves be of non-hygienic genotypes, significantly reducing the effectiveness of a breeding programme in terms of the response that can be obtained in one generation of selection. A breeding programme that also incorporates intracolony selection by selectively using queens from hygienic patrilines could thus be advantageous, especially at the start of a breeding programme when unselected colonies contain considerable variation for the trait of interest.

The aim of this study was to investigate whether intracolony selection can be used to improve a honeybeebreeding programme. A single generation breeding programme was carried out in four stages: (1) hygienic colonies were identified in an unselected population using freeze-killed brood as a bioassay of hygienic behaviour; (2) individual workers in these colonies that performed most hygienic behaviour were identified using observation hives; (3) the workers were genotyped to identify hygienic and non-hygienic patrilines and queens of these patrilines were reared; (4) the queens were mated in a semi-isolated valley with drones from a hygienic colony and allowed to establish colonies. The hygienic behaviour of the colonies headed by queens of hygienic and non-hygienic patrilines and the three original breeder colonies were then compared.

\section{Materials and methods}

\section{Stage 1: identifying and selecting hygienic colonies}

During May 2004, thirty-one queen-right honeybee colonies (Apis mellifera mellifera) were relocated to an apiary (Platt's Farm, Bamford, Derbyshire, UK). The size of the colonies was standardized to 6-7 frames covered in adult bees and brood, plus honey and pollen, each housed in a Langstroth hive box containing 10 mediumdepth frames. The hygienic behaviour of these colonies was measured using the freeze-killed brood assay (FKB; Spivak and Downey, 1998). Two patches of sealed brood each containing approximately 200 young pupae (white to purple eyes), approximately 3.5-6.5 days after cell capping, were located on a single frame from each colony. A metal cylinder $(8.3 \mathrm{~cm}$ diameter and $10 \mathrm{~cm}$ length) was twisted into the sealed brood until it reached the midrib. Liquid nitrogen $(300 \mathrm{ml})$ was poured slowly into the cylinder to kill the brood in the area selected. After 5-10 min, the nitrogen had evaporated and the cylinder was removed. Photographs of each patch were then taken and the frame was returned to its hive. Fortyeight hours later, the frame was removed and the patches were photographed again to determine the number of dead pupae that had been removed. As there is great variability in hygienic behaviour, even within a single colony, each colony was screened three times at weekly intervals. On the basis of the results of this bioassay, the three most hygienic colonies were selected as breeders. Two were used to rear virgin queens (T14 and T19), and one to produce drones (N14).

\section{Stage 2: identification of hygienic workers}

One observation hive was setup using bees and brood from colony T14 and a second from T19. Each contained one comb of honey and pollen, an empty comb, approximately 2000 unmarked bees from the parent colony and a laying marked queen from another colony. Cohorts of marked workers of known age from the parent breeder colonies were then added. These were obtained by transferring one frame of pupae from each colony into individual boxes kept in an incubator at $34{ }^{\circ} \mathrm{C}$ and $50 \%$ relative humidity. Within a few hours of emergence from their cells, young workers were marked with a numbered tag on the thorax and added to their respective observation hive. Over a period of 2 days, 592 and 634 workers were marked and introduced into the T14 and T19 observation hives, respectively.

When the marked workers were aged between 15 and 17 days, around the age that workers perform hygienic behaviour (Arathi et al., 2000), FKB assays were 
conducted in each observation hive. To do this, a frame with a patch of FKB (approximately 40 pupae) was introduced into the observation hive daily in exchange for the frame used the previous day. Starting $1 \mathrm{~h}$ after the frame had been introduced, the behaviour of workers on the FKB area was videoed (from 0900 to 2100 hours daily) until all the FKB had been removed. The behaviours seen were classified according to the criteria used by Arathi et al. (2000): 'uncapping' (a worker removed the wax capping from a cell in which there was a dead pupa); 'removing' (a worker removed a dead pupa); 'inspecting' (a worker placed its head inside a cell or entered it); 'walking' (a worker moved over the brood area without engaging in one of the above three behaviours). The marked bees were then collected and stored at $-20^{\circ} \mathrm{C}$.

\section{Stage 3: genotyping of hygienic workers and virgin queens}

For each of the breeder colonies T14 and T19, the 90 marked workers that performed hygienic behaviour most frequently were genotyped following the protocol of Châline et al. (2004). Briefly, DNA was extracted from an antenna using Chelex 100 (Bio-Rad, Hemel Hempstead, Hertfordshire, UK) and amplified at four highly polymorphic microsatellites markers: Am043, Am056, Am059 and Am061 (Estoup et al., 1994; Solignac et al., 2003). PCR conditions and reagents were as described by Châline et al. (2004). PCR products were run on a 3730 capillary sequencer (ABI, Warrington, Cheshire, UK). Allele sizes were scored by comparison with internal size markers and the multi-locus genotypes were used to infer the genotypes of the colony queens and their multiple mates. The patrilines of the genotyped workers were then determined based on their paternal alleles, and hygienic and non-hygienic patrilines were identified based on the behavioural data.

Virgin queens were reared from colonies T14 and T19 following standard queen-rearing procedures and allowed to emerge in an incubator at $34^{\circ} \mathrm{C}$. Immediately after emergence, each queen was individually marked, and the tip of each forewing was removed using fine scissors. The wingtips were genotyped (Châline et al., 2004) to determine which queens belonged to the hygienic and non-hygienic patrilines identified above. The queens were then held for 3 days in individual mailing cages with 4-5 attendant workers and candy at room temperature while the genotyping was conducted. For colonies T14 and T19, respectively, 130 and 148 queens were successfully reared and genotyped in this way.

\section{Stage 4: semi-controlled mating and final assessment}

Of the virgin queens reared in Stage 3, 60 from each of the two breeder colonies were selected on the basis of belonging either to the three highly hygienic patrilines identified in stage 3 (D in T14; A and I in T19) or to one of the five patrilines that were recorded performing hygienic behaviour only infrequently (B, G and J in T14; D and H in T19). These queens were introduced into 120 mating hives ( $\approx 2000$ workers, 5 medium Langstroth frames) using mailing cages (Pérez-Sato and Ratnieks, 2006). The ages of queens ranged from 3-7 days at the time of introduction, and any queens that failed to be accepted were replaced with another queen of known patriline. The mating hives were then placed in July 2004 at an apiary (Whitmore Lea Farm, Barber Booth) in the Edale Valley (Derbyshire, England), which is semi-isolated from natural mating interactions with honeybee colonies outside the valley (Jensen et al., 2005). The third breeder colony, N14, was also located at the mating apiary to provide drones for the queens to mate with. During the two previous months, this colony had been fed frequently with sugar syrup and frames with drone cells were added as needed to ensure that large numbers of drone eggs were laid by the queen. To increase the production of drones from this breeder queen, approximately every week, when the two drone frames were full with eggs and larvae, they were transferred above the queen excluders into three other hives, also located at the mating apiary, for rearing. The queens in these three hives were confined to a brood chamber without drone cells to lay in, so that these colonies reared only drones from the breeder colony. In this way, four hives' worth of drones from one queen were present during the mating period.

The mating hives that resulted in mated queens were allowed to build up during September to October 2004 and overwintered in a second apiary at Losehill Hall (Castelton, Derbyshire). During May and June 2005, all 26 surviving colonies (14 and 12 headed by queens reared from colonies T14 and T19, respectively, with half being from hygienic and half non-hygienic patrilines) were tested three times, at weekly intervals, for hygienic behaviour using $\mathrm{FKB}$ as in stage 1. In addition, the original three breeder hives were tested again.

\section{Statistical analyses}

A multivariate analysis of variance was used to compare the intensity of hygienic behaviour $\left(\log _{10}\right.$ transformed number of times each individual worker bee was observed performing each hygienic behaviour) exhibited by each patriline in stage 2 . In stage 3, G tests for heterogeneity were used to examine the frequencies of each patriline in the hygienic bees (from the observation hive data). A repeated-measures ANOVA on arc-sign transformed data was used to compare the proportions of brood removed between colonies in the FKB assays in stage 4.

\section{Results}

Stage 1: selection at the colony level

In the 31 colonies tested, the average proportion of FKB removed ranged from 15 to $98 \%$ and followed a bimodal distribution. Most colonies (65\%) removed $<50 \%$ of FKB within $48 \mathrm{~h}$. Seven colonies $(22 \%)$ were in the second mode, removing $>70 \%$ of FKB and were thus classified as being hygienic. Only one colony (N14) was very highly hygienic removing $98 \pm 1 \%$ of FKB. The other two colonies selected for the breeding programme, T14 and T19, removed $72 \pm 6 \%$ and $78 \pm 5 \%$, respectively.

Stage 2: hygienic behaviour in observation hives Approximately $35 \%$ and $24 \%$ of the marked workers that were originally introduced into the T14 and T19 observation colonies, respectively, disappeared during the experimental period. Of the marked workers that were seen on the FKB area (300 individuals in T14 and 409 in T19), most were seen uncapping and inspecting 
cells (T14: 205 individuals (68\%); T19: 225 (55\%)), inspecting (T14: 15 (5\%); T19: 51 (12\%)) or walking (T14: 69 (23\%); T19: $124(30 \%))$. Only a small proportion (T14: 11 (3\%); T19: 9 (2\%)) was ever seen performing full hygienic behaviour (uncapping and removing). There was a similar pattern in the intensity of hygienic behaviour performed, with the majority of bees (T14: 125 out of 216 (57\%); T19: 126 out of 234 (54\%)) performing hygienic behaviour less than five times, whereas a very few bees performed hygienic behaviour frequently (40-75 times; T14: 7 out of 216 (3\%); T19: 7 out of $234(3 \%))$.

\section{Stage 3: genotyping of hygienic workers and virgin}

\section{queens}

Intracolony kin structure and worker behaviour: From the genetic analysis of the 90 selected workers, we found that colonies T14 and T19 had 11 and 9 patrilines, respectively. In colony $\mathrm{T} 14$, patriline $\mathrm{D}$ was most frequently seen engaged in hygienic behaviour (Figure 1). In colony T19, patrilines A and I were more frequently seen being hygienic than the other patrilines (Figure 1). Similarly, patrilines within colonies also differed in the intensity of the four hygienic behaviours they performed with patriline D of colony T14, and patrilines A and I of colony T19, again showing the highest levels of hygienic behaviour (T14: $F_{36,312}=1.94$, $P<0.001 ;$ T19: $F_{20,324}=1.58, P=0.038$; Figure 2).
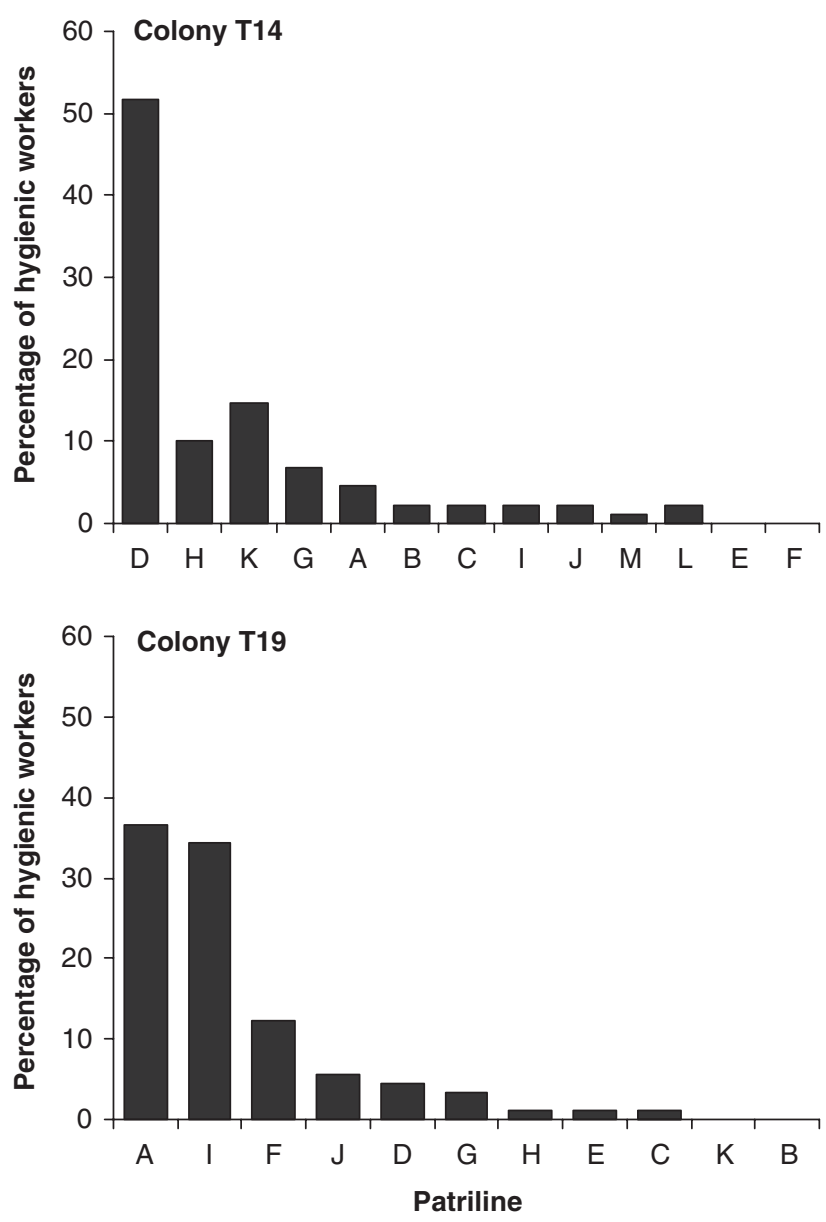

Figure 1 Percentage of hygienic bees that belonged to each patriline in colonies T14 and T19, as determined during stage 3.
Stage 4: semi-controlled mating and final assessment Overall, $38 \%$ of the genotyped queens were rejected when introduced, $61 \%$ of those accepted did not mate and $43 \%$ of those that mated did not survive the winter, leaving 26 alive the following spring. Of these, the colonies headed by queens of hygienic patrilines removed approximately twice as many FKB as colonies

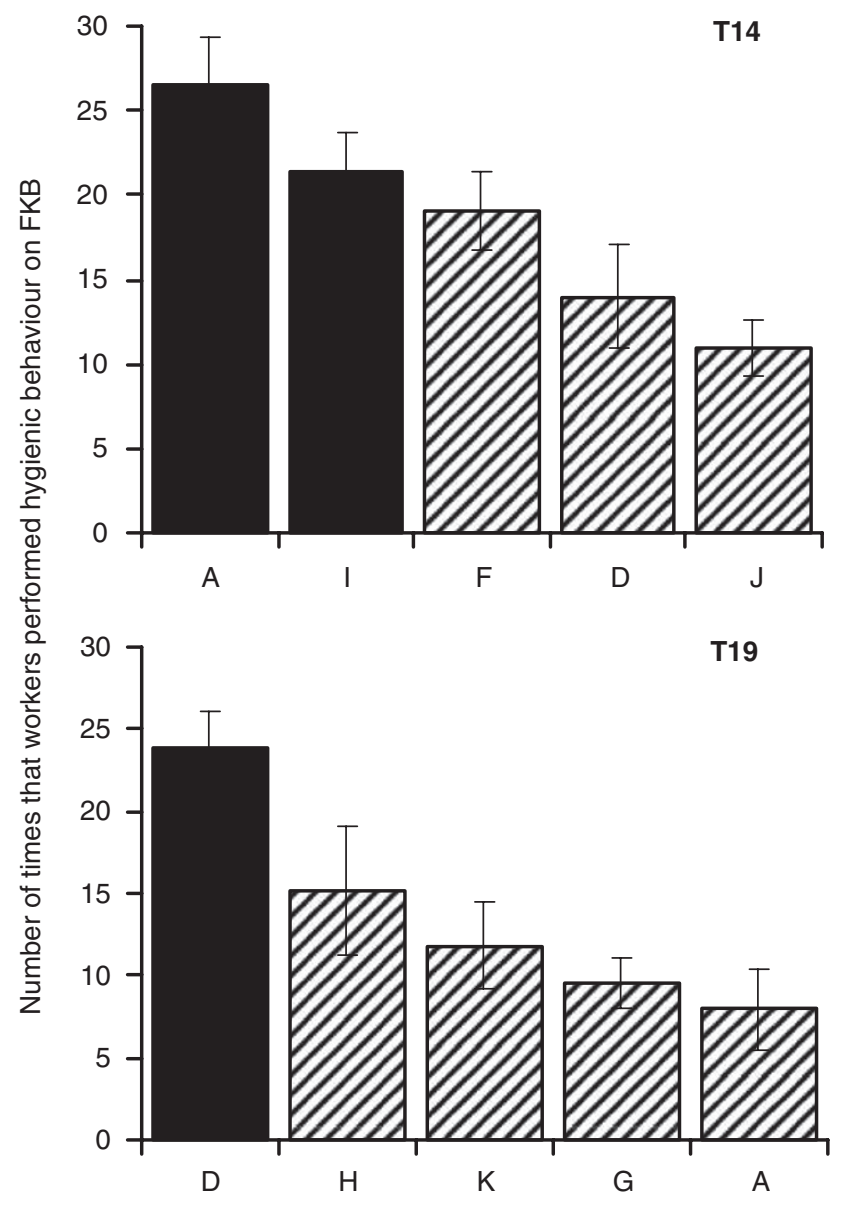

Figure 2 Mean \pm s.e. number of times that genotyped workers were seen performing hygienic behaviour (inspecting and uncapping) on patches of freeze-killed brood in observation hives. Patrilines for which less than three workers were observed have been excluded.

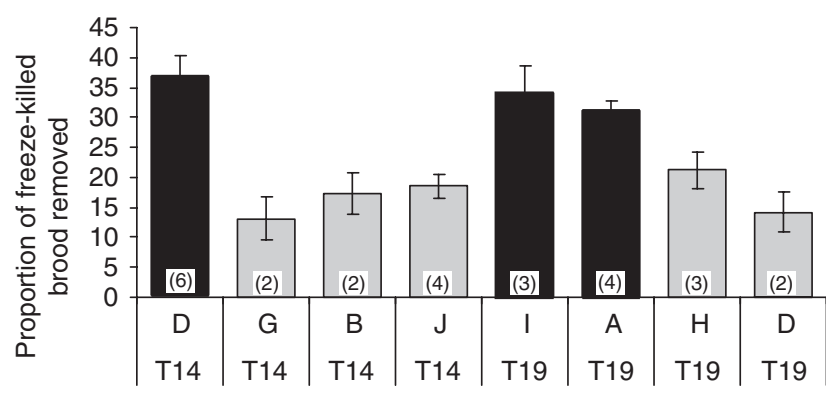

Parentage (patriline and colony) of mother queen

Figure 3 Mean \pm s.e. proportion of freeze-killed brood removed within $48 \mathrm{~h}$ in stage 4 , spring 2005 , in colonies headed by queens from hygienic (black columns) and non-hygienic patrilines (grey columns). The numbers of colonies in each patriline are given in parentheses. 

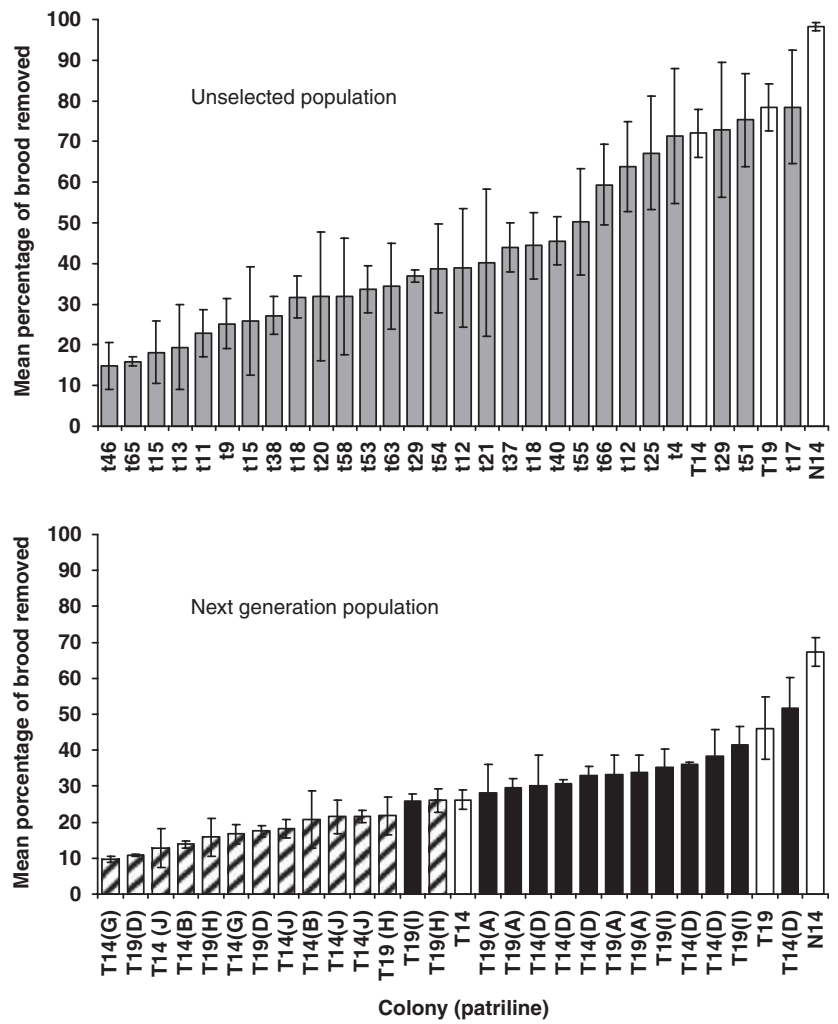

Figure 4 Mean \pm s.e. proportion of freeze-killed brood removed within $48 \mathrm{~h}$ by unselected colonies (above, stage 1, screened in May 2004), and the colonies that resulted from the breeding programme (below, stage 4, screened in May 2005). Included in both histograms are the three breeder colonies (T14, T19, N14), which were tested at both times and thus show the environmental difference between years. Unselected colony, grey columns; breeder colony, white columns; colonies headed by queens from non-hygienic patrilines, striped columns; colonies headed by queens from hygienic patrilines, black columns.

headed by queens of non-hygienic patrilines $\left(\mathrm{F}_{1,50}=66.4\right.$, $P<0.0001$; Figure 3). In addition, when these daughter colonies are ranked by their levels of hygienic behaviour, it can be seen that the distributions for colonies headed by hygienic and non-hygienic patriline queens were almost entirely distinct (Figure 4). The three breeder colonies, T14, T19 and N14, removed 26, 46 and $67 \%$ of the FKB, respectively. In general, hygienic behaviour was much lower during the post-selection assessment than during the previous spring, with the three breeder colonies (which were tested during both periods) all showing significantly lower hygienic behaviour $\left(\mathrm{F}_{1,6}=31.7, P=0.001\right)$.

\section{Discussion}

The results show that it is possible to carry out intracolony selection during a breeding programme for hygienic behaviour. The genotyping carried out in stage 3 highlights the importance of doing this by showing that in the two breeder colonies used for rearing queens, only one or two of the 11 or 9 patrilines had highly hygienic workers. Other studies have similarly found that hygienic genotypes are rare (Milne, 1985; Spivak and Reuter, 2001; Waite et al., 2003a). Our results not only
Multi-level selection in honeybees

JA Pérez-Sato et al

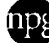

confirm that there is a heritable component to hygienic behaviour, but also show that intracolony selection is most likely to be especially useful when first selecting for hygienic bees, given that hygienic colonies are a small minority of all colonies, and that within these hygienic colonies, most of the patrilines are most likely to be non-hygienic. The results from stage 4 confirm that intracolony selection resulted in more hygienic daughter colonies when colonies were headed by queens of hygienic versus non-hygienic patrilines. Colonies headed by queens from hygienic patrilines removed twice as many FKB $(34 \%)$ as colonies headed by queens from nonhygienic patrilines $(17 \%)$. Furthermore, the levels of hygienic behaviour shown by almost all of the colonies headed by queens of hygienic patrilines were greater than of those headed by queens of non-hygienic patrilines.

The study suffered from several technical difficulties, which suggest that multi-level selection can be more successful than we achieved. The high mortality during introduction could be reduced by using better introduction methods (for example, Pérez-Sato et al., 2007, 2008). The high mortality during the mating flights may be related to the removal of wing tips for genotyping, and the use instead of non-destructive sources of DNA, such as pupal exuviae (Gregory and Rinderer, 2004), would therefore be advisable for genotyping virgin queens. Many of the matings themselves were to non-target drones because the Edale Valley Site is only semi-isolated from other honeybees (Jensen et al., 2005). This did not bias our results because the effect was equal for queens from hygienic and non-hygienic patrilines, but the effectiveness of the selection regime would be improved by using fully isolated mating apiaries or artificial insemination to ensure that all queens are mated with males from the hygienic breeder colony. Finally, the general levels of hygienic behaviour during the final assays in 2005 were rather low, including the breeder colonies. This was most likely due to relatively high levels of chalkbrood (a parasitic fungus that kills bee larvae) that spring, which meant that the bees also had many chalkbrood-killed brood to deal with during the assays. The result of these various problems was that although the sample size obtained at stage 4 was sufficient, it was smaller than planned (26 colonies), and the overall levels of hygienic behaviour were reduced. The fact that statistically significant differences in hygienic behaviour were observed in spite of the reduced sample size shows the large effect produced by multi-level selection.

The normal honeybee breeding method in which whole colonies are identified as breeders requires at least four generations of artificial selection to obtain a population of hygienic bees (Palacio et al., 2000; Spivak and Reuter, 2001); yet only a single generation per year is possible in most temperate areas. As this study shows, by increasing the genetic relatedness between mother and daughter colonies from 0.15 to 0.375 , one generation of multi-level selection was sufficient to produce colonies that were twice as hygienic as colonies from random patrilines. This is particularly impressive given the fact that this was the first time that intracolony selection had been tried and that some beekeeping problems arose that could be circumvented in future use of the method. Hygienic behaviour is effective against a spectrum of 
honeybee diseases, and breeding for the trait is particularly pertinent given the recent damage caused by the emerging disease syndrome known as Colony Collapse Disorder in the USA (Cox-Foster et al., 2007). Multi-level selection is also applicable for other heritable traits in honeybee breeding, particularly those in which the overall colony phenotype is disproportionately affected by the genotypes of a minority of workers, as with hygienic behaviour. Colony defensiveness (tendency to sting), for instance, also involves very few highly defensive bees from particular genotypes (Giray et al., 2000; Hunt et al., 2003), so multi-level selection for lessdefensive bees is most likely to be successful, although here it would be to avoid a few unsuitable patrilines rather than to use a few suitable patrilines. Multi-level selection will also be effective for traits that act at the individual level, such as individual larval resistance to disease (Palmer and Oldroyd, 2003). The method may be less effective for traits that result more from the interactions of multiple genotypes, such as foraging behaviour (Chapman et al., 2007), or traits where the characteristics of individual workers cannot easily be determined. The technique of multi-level selection we have shown here therefore has considerable potential for making honeybee breeding a more viable proposition. This is particularly important in the face of the growing threat from emerging diseases to the honeybee populations of many countries, and the agricultural crops that their pollination services support.

\section{Acknowledgements}

We are grateful to George Platt, John Neild and the Peak District National Park for providing the Bamford, Edale and Losehill Hall apiaries, respectively, and to the four referees for their constructive comments. The research was supported by a PhD scholarship to JAP-S from CONACyT and the Colegio de Postgraduados, by a Marie Curie Outgoing International Fellowship to WOHH within the 6th European Community Framework Programme, and by the EU (FW5-ENV) research network 'Beekeeping and Apis Biodiversity in Europe' (BABE) (contract EVK2-CT-2000-00068).

\section{References}

Arathi HS, Burns I, Spivak M (2000). Ethology of hygienic behaviour in the honey bee Apis mellifera L. (Hymenoptera: Apidae): behavioural repertoire of hygienic bees. Ethology 106: 365-379.

Beban H (2003). Import Risk Analysis: Honey Bee (Apis mellifera) Genetic Material. MAFF Biosecurity Authority: Wellington, New Zealand.

Bienefeld K, Ehrhardt K, Reinhardt F (2007). Genetic evaluation in the honey bee considering queen and worker effects-a BLUP-animal model approach. Apidologie 38: 77-85.

Bienefeld K, Pirchner F (1991). Genetic correlations among several colony characters in the honey bee (Hymenoptera, Apidae) taking queen and worker effects into account. Ann Entomol Soc Am 84: 324-331.

Châline N, Ratnieks FLW, Raine NE, Badcock NS, Burke T (2004). Non-lethal sampling of honey bee, Apis mellifera, DNA using wing tips. Apidologie 35: 311-318.

Chapman NC, Oldroyd BP, Hughes WOH (2007). Differential responses of honeybee (Apis mellifera) patrilines to changes in stimuli for the generalist tasks of nursing and foraging. Behav Ecol Sociobiol 61: 1185-1194.
Committee on the Status of Pollinators in North America NRC (2007). Status of Pollinators in North America. National Academies Press.

Cox-Foster DL, Conlan S, Holmes EC, Palacios G, Evans JD, Moran NA et al. (2007). A metagenomic survey of microbes in honey bee Colony Collapse Disorder. Science 318: 283-287.

Ellis JD, Munn PA (2005). The worldwide health status of honey bees. Bee World 86: 88-101.

Estoup A, Solignac M, Cornuet JM (1994). Precise assessment of the number of patrilines and of genetic relatedness in honeybee colonies. Proc $R$ Soc Lond B 258: 1-7.

Floris I, Cabras P, Garau VL, Minelli EV, Satta A, Troullier J (2001). Persistence and effectiveness of pyrethroids in plastic strips against Varroa jacobsoni (Acari: Varroidae) and mite resistance in a Mediterranean area. J Econ Entomol 94: 806-810.

Franck P, Coussy H, Le Conte Y, Solignac R, Garnery L, Cornuet JM (1999). Microsatellite analysis of sperm admixture in honeybee. Insect Mol Biol 8: 419-421.

Franck P, Solignac M, Vautrin D, Cornuet JM, Koeniger G, Koeniger N (2002). Sperm competition and last-male precedence in the honeybee. Anim Behav 64: 503-509.

Giray T, Guzman-Novoa E, Aron CW, Zelinsky B, Fahrbach SE, Robinson GE (2000). Genetic variation in worker temporal polyethism and colony defensiveness in the honey bee, Apis mellifera. Behav Ecol 11: 44-55.

Gregory PG, Rinderer TE (2004). Non-destructive sources of DNA used to genotype honey bee (Apis mellifera) queens. Ent Exp Appl 111: 173-177.

Hunt GJ, Guzman-Novoa E, Uribe-Rubio JL, Prieto-Merlos D (2003). Genotype-environment interactions in honeybee guarding behaviour. Anim Behav 66: 459-467.

Jensen AB, Palmer KA, Châline N, Raine NE, Tofilski A, Martin SJ et al. (2005). Quantifying honey bee mating range and isolation in semi-isolated valleys by DNA microsatellite paternity analysis. Conserv Genet 6: 527-537.

Lodesani M, Costa M (2005). Limits of chemotherapy in beekeeping: development of resistance and the problem of residues. Bee World 86: 102-109.

Milne CP (1983). Honey bee (Hymenoptera, Apidae) hygienic behavior and resistance to chalkbrood. Ann Entomol Soc Am 76: 384-387.

Milne CP (1985). Estimates of the heritabilities of and genetic correlation between 2 components of honey bee (Hymenoptera, Apidae) hygienic behaviour-uncapping and removing. Ann Entomol Soc Am 78: 841-844.

Oldroyd BP (1996). Evaluation of Australian commercial honey bees for hygienic behaviour, a critical character for tolerance to chalkbrood. Aust J Exp Agricult 36: 625-629.

Palacio MA, Figini EE, Ruffinengo SR, Rodriguez EM, del Hoyo ML, Bedascarrasbure EL (2000). Changes in a population of Apis mellifera L. selected for hygienic behaviour and its relation to brood disease tolerance. Apidologie 31: 471-478.

Palmer KA, Oldroyd BP (2003). Evidence for intra-colonial genetic variance in resistance to American foulbrood of honey bees (Apis mellifera): further support for the parasite/ pathogen hypothesis for the evolution of polyandry. Naturwiss 90: 265-268.

Pérez-Sato JA, Hughes WOH, Couvillon MJ, Ratnieks FLW (2007). Improved technique for introducing four-day old virgin queens to mating hives that uses artificial and natural queen cells for introduction. J Apic Res 46: 28-33.

Pérez-Sato JA, Kärcher MH, Hughes WOH, Ratnieks FLW (2008). Direct introduction of mated and virgin queens using smoke: a method that gives almost $100 \%$ acceptance when hives have been queenless for 2 days or more. J Apic Res 47: 243-250.

Pérez-Sato JA, Ratnieks FLW (2006). Comparing alternative methods of introducing virgin queens (Apis mellifera) into mating nucleus hives. Apidologie 37: 571-576. 
Ratnieks FLW (1998). Why breeding bees is different. Bee Improvement 2: 6-7.

Rothenbuhler WC (1964). Behaviour genetics of nest cleaning in honey bees. I. Responses of 4 inbred lines to disease-killed brood. Anim Behav 12: 578-583.

Solignac M, Vautrin D, Loiseau A, Mougel F, Baudry E, Estoup A et al. (2003). Five hundred and fifty microsatellite markers for the study of the honeybee (Apis mellifera L.) genome. Mol Ecol Notes 3: 307-311.

Spivak M (1996). Honey bee hygienic behavior and defense against Varroa jacobsoni. Apidologie 27: 245-260.

Spivak M, Downey DL (1998). Field assays for hygienic behavior in honey bees (Hymenoptera: Apidae). J Econ Entomol 91: 64-70.

Spivak M, Gilliam M (1998). Hygienic behaviour of honey bees and its application for control of brood diseases and varroaPart II. Studies on hygienic behaviour since the Rothenbuhler era. Bee World 79: 169-186.
Spivak M, Reuter GS (2001). Varroa destructor infestation in untreated honey bee (Hymenoptera: Apidae) colonies selected for hygienic behavior. J Econ Entomol 94: 326-331.

Tarpy DR, Nielsen R, Nielsen DI (2004). A scientific note on the revised estimates of effective paternity frequency in Apis. Insectes Soc 51: 203-204.

Waite R, Brown M, Thompson H (2003a). Hygienic behaviour in honey bees in the UK: a preliminary study. Bee World 84: 19-26.

Waite R, Tomkies V, Flint J, Danks C, Brown M, Thompson H (2003b). Bee Health Report. Central Science Laboratory, Sand Hutton, UK.

Wilkins S, Brown MA, Cuthbertson AGS (2007). The incidence of honey bee pests and diseases in England and Wales. Pest Manag Sci 63: 1062-1068.

Yue C, Schroder M, Bienefeld K, Genersch E (2006). Detection of viral sequences in semen of honeybees (Apis mellifera): evidence for vertical transmission of viruses through drones. J Invertebr Pathol 92: 105-108. 